The Effect of Dysfunctional Thought Processes on Subjective Well-Being and Job Satisfaction

\author{
Timothy A. Judge \\ Center for Advanced Human Resource Studies \\ New York State School of Industrial and Labor Relations \\ Cornell University
}

\author{
Edwin A. Locke \\ Department of Management \\ College of Business Administration \\ University of Maryland
}

Running Head: DYSFUNCTIONAL THOUGHT PROCESSES 


\begin{abstract}
While the dispositional approach to job satisfaction has received a good deal of recent attention, a fundamental deficiency in past dispositional research is a failure to use existing theories to explain why individuals are unhappy and dissatisfied with their jobs. Locke (1976), Judge (in press), and Judge and Hulin (in press) suggested that thinking processes should be studied in relation to job satisfaction. This study tested the thesis that the cognitive theory of depression, which focuses on irrational thought processes, will help in understanding both subjective well-being and job satisfaction. A causal model involving subjective well-being, job satisfaction, dysfunctional thought processes, and other relevant influences was hypothesized and tested using a stratified random sample of university employees. Ratings were obtained from two sources in order to reduce single-source bias. The results indicated strong support for the overall model and for the efficacy of dysfunctional thought processes.
\end{abstract}




\section{The Effect of Dysfunctional Thought Processes on Subjective Well-Being and Job Satisfaction}

In a recent review of the literature on dispositional sources of job satisfaction, Judge (in press) argued that much of the research linking dispositional states to job satisfaction is atheoretical in nature. He argued that virtually no dispositional research has attempted to explain, drawing from existing theories of social cognition or attitude formation, why individuals are unhappy in general or dissatisfied with their jobs. Judge (in press) argued that such a deficiency in past dispositional research is regrettable, since established theories from personality and social psychology may have a great deal to offer in terms of explaining how affective states are formed. The importance of understanding the psychology behind dispositional effects on job satisfaction was also recently emphasized by Weiss (1991).

Locke (1976) and Judge and Hulin (in press) suggested that thinking processes may influence subjective well-being and job satisfaction, although they did not propose an actual theory. A potentially relevant theory is the cognitive theory of depression (Beck, 1963, 1987), which has been one of the most influential theories in the areas of counseling and clinical psychology. This theory maintains that erroneous thought processes such as overgeneralization, perfectionism, and dependence on others are an important cause of depression (and thus, by necessity, unhappiness). The purpose of the present study is to investigate the role of dysfunctional thought processes in affecting subjective well-being and job satisfaction. Based on relevant theory and past research, a causal model was proposed and tested relating dysfunctional thought processes, subjective well-being, and job satisfaction.

\section{Relevant Theory and Past Research}

\section{Cognitive Theory of Depression}

The cognitive theory of depression holds that the way individuals think is a source of unhappiness. Specifically, depressed or unhappy individuals are hypothesized to have repetitive, automatized thoughts (Beck, 1987) which are irrational and dysfunctional in 
nature. The irrational beliefs or processes are manifested in such cognitive tendencies as overgeneralization (e.g., "If I do a bad thing, it means I am a bad person"), perfectionism (e.g., "If I am any good, I should be able to excel at anything I attempt"), dependence on others (e.g., "If people whom I care about do not care for me, it is awful"), and desire for social approval (e.g., "I often do things to please others rather than myself"). Dysfunctional thoughts make individuals vulnerable to depression because they undermine self-worth (Kuiper \& Olinger, 1986; Kuiper, Olinger, \& Swallow, 1987). For example, believing one must be good at everything guarantees failure. Trying for the approval of others leads one to sacrifice one's own judgment and values. Thus, depression or unhappiness results from these thinking styles.

From a psychological perspective, dysfunctional thought processes comprise cognitive habits or beliefs that screen, code, categorize, and evaluate information inappropriately (Keller, 1983). Treatment of depression or unhappiness, therefore, begins with identification of the dysfunctional beliefs that lead to depression or unhappiness. Attempts are then made to expose and test the individual's erroneous beliefs and methods of processing information. Finally, individuals are shown how to alter their dysfunctional attitudes and thought processes (Beck, Rush, Shaw, \& Emery, 1979; Keller, 1983).

Recently, Haaga, Dyck, and Ernst (1991) have provided a review of the empirical evidence on the cognitive theory of depression. Cognitive theory, to be empirically supported, requires that a number of testable hypotheses be supported. The more important among these, as reviewed by Haaga et al. (1991), are: negativity (unhappy people's thoughts are more negative than those of happy people); automaticity (negative cognitions are unintended, repetitive, and automatized); association with noncognitive symptoms (negative cognitions are associated with symptoms of depression or unhappiness); and information processing biases (negative cognitions reflect biases in the processing of information such as selective memory and cognitive distortions). 
In reviewing the empirical status of these hypotheses, Haaga et al. (1991) found substantial support for them by past research. Specifically, those who have more dysfunctional cognitions are more likely to be unhappy or depressed than those who have fewer such cognitions (Crandell \& Chambless, 1986; Dobson \& Shaw, 1986). Similarly, the automaticity of cognitive processes has been upheld (Bargh \& Tota, 1988; Wenzlaff, Wegner, \& Roper, 1988). Haaga et al. (1991) review a large number of studies supporting another assumption, that dysfunctional cognitions lead to depression or unhappiness. Finally, some support is indicated for the hypothesis that those who are unhappy or depressed cognitively distort information or are biased in their recall and interpretation of information (Ingram, 1990; Lewinsohn \& Rosenbaum, 1987). In sum, Haaga et al.'s (1991) results are supportive of the validity of the cognitive theory of depression. Furthermore, considerable empirical support exists regarding the validity of cognitive therapy in reducing depression or unhappiness (Dobson, 1989). Despite the apparent efficacy of the theory in explaining why individuals become unhappy with themselves, and, by implication, their jobs, the cognitive theory of depression has not been tested as a potential explanatory factor in dispositional or job satisfaction research.

\section{Affective Disposition. Subjective Well-Being, and Job Satisfaction}

Recently, a number of researchers (Davis-Blake \& Pfeffer, 1989; Gerhart, 1987, 1990; Judge, in press; Judge \& Hulin, in press) have argued that while past dispositional research (Arvey, Bouchard, Segal, \& Abraham, 1989; Levin \& Stokes, 1989; Pulakos \& Schmitt, 1983; Staw \& Ross, 1985; Staw, Bell, \& Clausen, 1986) has made an important contribution to the knowledge base concerning determinants of job satisfaction, it has suffered from conceptual ambiguities. In particular, Judge (in press) and Judge and Hulin (in press) argued that a clearer distinction needed to be made between the general disposition to be satisfied (affective disposition) and how happy an individual currently is with his or her life. 
Judge and Hulin (in press) defined affective disposition as the tendency to respond to classes of environmental stimuli in a predetermined, affect-based manner. This may be closer to a dispositional construct than concepts which represent current affective states. Specifically, dispositional researchers have often assumed that negative affectivity (Watson \& Clark, 1984) is the appropriate dispositional construct (Brief, Burke, George, Robinson, \& Webster, 1988; George, 1989; Levin \& Stokes, 1989). However, the tendency to respond to the environment in an affect-based manner (affective disposition) is not the same as how happy an individual currently is or is not (as measured by positive/negative affect or subjective well-being). Dispositional tendencies may be thwarted or enhanced by numerous factors in the environment and in the person.

Subjective well-being represents an ongoing state of psychological wellness (Diener, 1984). While Judge and Hulin (in press) maintained that the disposition toward affect (affective disposition) is different from experienced affect (subjective well-being), the authors hypothesized that the predisposition to be happy or satisfied in general should influence the current level of happiness in individuals.

Drawing from Weitz (1952), Judge and Hulin (in press) measured affective disposition by assessing how satisfied the respondent was with a list of predominantly neutral or innocuous objects common to everyday life (e.g., one's telephone number, one's first name, $81 / 2^{\prime \prime} \times 11^{\prime \prime}$ paper). Individuals highly satisfied with the objects as a whole may have a tendency to see most things (including themselves and their lives) in a favorable light. The obverse is true as well. Results by Judge and Hulin (in press) suggested that their measure of affective disposition was distinct from measurements of subjective wellbeing.

In addition to investigating the relationship between affective disposition and subjective well-being, Judge and Hulin (in press) further hypothesized that subjective wellbeing and job satisfaction were mutually causative. Testing the relationship between affective disposition, subjective well-being, and job satisfaction using a sample of nurses, 
Judge and Hulin (in press) found that affective disposition significantly influenced subjective well-being. Further, the reciprocal relationship between subjective well-being and job satisfaction was supported. These results suggest that it is important to distinguish between the disposition toward affect and affect actually experienced. Equally important, the relationship between subjective well-being and job satisfaction appears to be bidirectional -- subjective well-being may be both a significant cause of, and effect on, job satisfaction.

A limitation in the Judge and Hulin (in press) study is that it provides little knowledge of the psychological process underlying the subjective well-being and job satisfaction relationship. While subjective well-being and job satisfaction clearly are psychological states, no effort was undertaken to understand the psychology behind the formation of these attitudes. Locke (1976) suggested that judgments of satisfaction and dissatisfaction with one's job and other life domains may derive from individuals' thought processes. Judge and Hulin (in press) suggested that such thought processes might influence both one's overall level of well-being and job satisfaction. However, Judge and Hulin (in press) could only suggest the possibility as an important area for future research. It represented an important suggestion, however, as it holds the possibility of providing a theoretical explanation underlying the formation of subjective well-being and job satisfaction.

\section{Causal Model}

In order to investigate the causal relationships between dysfunctional thought processes, subjective well-being, and job satisfaction, a causal model was hypothesized. These relations were embedded in a network of other constructs to avoid omitted variable bias (James, Mulaik, \& Brett, 1982). The hypothesized structural model is displayed in Figure 1. Rectangles in the figure represent exogenous or independent variables. Circles represent endogenous or dependent variables. The links in this model are discussed below; the more critical links are discussed first. 


\section{Insert Figure 1 About Here}

\section{Dysfunctional Thought Processes to Subjective Well-Being}

Probably the most important assumption of the cognitive theory of depression is that dysfunctional cognitive processes are a primary source of unhappiness. A considerable amount of research suggests that dysfunctional thought processes lead to depression or unhappiness (Kuiper et al., 1987; Olinger, Kuiper, \& Shaw, 1987; Wierzbicki \& Rexford, 1989; Wise \& Barnes, 1986). Because these thought processes reflect negative views and methods of thinking that are unhealthy, unhappiness or depression often results. For example, holding oneself to a perfect standard, believing that all mistakes impeach one's character, and sacrificing one's self-fulfillment for others are all unhealthy attitudes that may manifest themselves personal worthlessness (Beck, 1967). Thus, individuals' thought processes or cognitive styles are hypothesized to induce unhappiness (i.e., low subjective well-being).

In hypothesizing the effect of dysfunctional thought processes on unhappiness, two relevant issues must be kept in mind. First, while many studies have linked depressive attitudes with dysfunctional cognitions, few studies have related these two concepts in a rigorous causal framework (Haaga et al., 1991). Hence, the causal link hypothesized here must be done so with some degree of caution. Second, the cognitive theory of depression is fully applicable to "normal" individuals (i.e., individuals without clinically diagnosed mental disorders) (Smith \& Allred, 1986). Therefore, it is appropriate to relate such thought processes to subjective well-being in a causal framework that applies to members of the work force.

\section{Subjective Well-being to Job Satisfaction}

A hypothesized causal link from subjective well-being to job satisfaction is included in Figure 1. Judge and Hulin's (in press) study, as well as past dispositional research (Levin 
\& Stokes, 1989; Pulakos \& Schmitt, 1983; Staw \& Ross, 1985; Staw et al., 1986; Weitz, 1952), provides support for hypothesizing that subjective well-being will influence job satisfaction. Thus, past empirical data support the effect of general affective states on job satisfaction.

There are several theoretical reasons why subjective well-being may influence job satisfaction. One possibility from cognitive psychology that may explain the dispositional effect is the following: subjective well-being, as the outcome of affective disposition, may influence how individuals collect and recall information about their job. Bower (1981) demonstrated this process with respect to life events. Motowidlo and Lawton (1984) and Porac (1987) have suggested a cognitive approach with respect to job attitudes, where certain dispositions can influence job affect. Thus, happy individuals may tend to store, evaluate, or recall job information differently from unhappy individuals. However, while this suggests that subjective well-being influences job satisfaction, a direct empirical test of the explanation is lacking.

\section{Job Satisfaction to Subjective Well-being}

A significant correlation between job and life satisfaction consistently has been found. In a recent meta-analytic review, Tait, Padgett, and Baldwin (1989) found the average correlation between job and life satisfaction, corrected for measurement error, to be .44 . Some researchers have interpreted the correlation between job and life satisfaction as evidence for a dispositional effect on job satisfaction (see Staw \& Ross, 1985). It is equally possible, however, that the causal direction is from job satisfaction to life satisfaction. In fact, Judge and Hulin (in press) found a significant causal effect of job satisfaction on subjective well-being. Estimating a nonrecursive relationship between subjective well-being and job satisfaction allows inferences regarding the causality between the two constructs.

Undoubtedly the reason behind the effect of job satisfaction on subjective wellbeing is the importance of work to individuals' lives. In fact, empirical evidence does 
support the moderating effect of job importance on the job and life satisfaction relationship (Iris \& Barrett, 1972; Rice, McFarlin, Hunt, \& Near, 1985). The centrality of work to individuals, whose roots may lie in the Protestant work ethic, probably derives from the fact that most individuals spend the majority of their waking hours at work. Having our identities and our time bound to work suggests its importance in judgments of subjective well-being.

\section{Job Dysfunctional Thought Processes to Job Satisfaction}

Locke (1976) speculated that individuals' thought processes may influence happiness or satisfaction derived from all domains of life. The link from dysfunctional thought processes to subjective well-being was reviewed earlier. However, Locke's (1976) arguments also suggest that dysfunctional thought processes may influence job satisfaction. This would be particularly true if the dysfunctional attitudes were oriented toward the job. Dysfunctional thought processes are expected to affect job satisfaction as mediated through subjective well-being. On the other hand, job dysfunctional thought processes are hypothesized to influence job satisfaction directly, because overgeneralizing about job experiences, holding one's job performance to a perfect standard, and so on, should cause individuals to be less happy about their jobs. Therefore, it is hypothesized that job dysfunctional attitudes, which are dysfunctional attitudes oriented toward the job, will negatively influence job satisfaction. Since the degree to which individuals think dysfunctionally about their job should be affected by the degree to which they think dysfunctionally in general, dysfunctional thought processes are hypothesized to influence job dysfunctional thought processes.

Job Satisfaction to Job Avoidance

Absenteeism, turnover, and lateness have often been described by organizational researchers as examples of employee withdrawal (Beehr \& Gupta, 1978; Porter \& Steers, 1973; Youngblood, 1984). Typically, research has investigated these behaviors in isolation. Job satisfaction has often been related to these isolated behaviors, with inconsistent results. 
Hulin (1991) and Fisher and Locke (in press) have argued that the prediction of job behaviors in isolation is limiting in that it provides little basis for generalizing to other job behaviors that may be functional equivalents or manifestations of the same underlying, general behavioral construct. In proposing a general behavioral construct, Hulin (1991) defined employee withdrawal as "the set of behaviors that dissatisfied individuals enact to avoid the work situation; they are behaviors designed to allow avoidance of participation in dissatisfying work situations (p. 476)." Hanisch and Hulin (1991), Roznowski and Hanisch (1990), and Roznowski, Rosse, and Miller (1991) reported data suggesting that individual withdrawal behaviors covary in such a manner as to suggest a general factor. Fisher and Locke (in press) found that a set of activities labeled as job and work avoidance were consistently related to job dissatisfaction.

In the present study job avoidance is hypothesized to be significantly influenced by job dissatisfaction. Job avoidance does not represent only actual withdrawal behaviors, but also intentions and the behavioral tendencies of individuals (Hanisch \& Hulin, 1991; Roznowski et al., 1991). Based on the theory of reasoned action or planned behavior (Ajzen, 1991; Fishbein \& Ajzen, 1974), such cognitions are assumed to lead to actual withdrawal behaviors. However, consistent with the psychological focus of the present research, the cognitions of the individual are of immediate interest.

\section{Other Causal Links}

The distinction between affective disposition and subjective well-being was reviewed earlier. It is hypothesized that the immediate outcome of affective disposition is not job satisfaction, but rather individuals' level of subjective well-being (see Figure 1). Those predisposed to view their environment in a positive manner are more likely to have a sense of contentment and happiness to their lives. Those predisposed to be critical of life's events and stimuli are expected to be unhappy and troubled. Accordingly, affective disposition is hypothesized to influence the general affective state of the individual. 
Four of the more important demographic influences on subjective well-being identified in Diener's (1984) review of the literature were age, race, marital status, and sex. The majority of recent evidence suggests that subjective well-being tends to increase with age (Diener, 1984), although the effects may be modest. Perhaps because of urbanicity and lower socioeconomic status, minorities generally have been found to have lower subjective well-being than whites (Andrews \& Withey, 1976; Diener, 1984). Diener (1984) suggested that "...virtually all relationships [between marital status and subjective well-being] are positive (pg. 556)." Although the effect of gender on subjective well-being has yielded inconsistent results, most research suggests that males are somewhat less happy than females (Diener, 1984). Finally, research suggests that employee assistance programs (EAPs), where employers sponsor counseling or treatment for personal problems (substance abuse, family conflicts, depression), result in higher levels of subjective wellbeing (Ramanathan, 1990). Thus, based on past research, these variables are hypothesized to influence subjective well-being, as represented in Figure 1.

Hulin, Roznowski, and Hachiya's (1985) model of job satisfaction and employee responses was used to select relevant influences on job satisfaction. Hulin et al. (1985) hypothesized that job satisfaction is a function of the difference between work-role inputs, what the individual contributes to the work role (e.g., time and effort), compared to role outcomes, what is received (e.g., pay, status, intrinsic factors). All else being equal, as outcomes received relative to inputs invested increase, job satisfaction is hypothesized to increase.

In the present study, education level and hours worked were selected as representations of work role inputs. Therefore, as shown in Figure 1, controlling for workrole outcomes, the more education the respondent has achieved, and the more hours worked, the lower the level of job satisfaction the individual is hypothesized to report. Wage rate and intrinsic factors were chosen as manifestations of work role outcomes, and were expected to influence job satisfaction positively. 
Hulin et al. (1985) further proposed that perceived labor market conditions will affect job satisfaction. In periods of high unemployment, for example, individuals will perceive their inputs as less valuable because there are others in the labor market willing to contribute their inputs. Therefore, as unemployment rises, the perceived value of inputs relative to outcomes declines, and job satisfaction increases. The converse is also hypothesized, where low unemployment (and many alternatives) reduces job satisfaction. In Figure 1, perceived time to find a job of comparable pay is expected to be positively related to job satisfaction; those who believe it would take a long time to find a comparable job are more likely to be happy with what they have.

Hulin et al. (1985) and Smith, Kendall, and Hulin (1969) have argued that individuals' frame of reference, which they defined as past experience with relevant outcomes, influence how individuals perceive current outcomes received. The fewer, or less valued, the outcomes received in the past, the greater the current job satisfaction. Figure 1 shows that, as a frame of reference variable, present wage compared to past is expected to relate positively to job satisfaction.

An unexplored variable in general and in job satisfaction research in particular is that of ambition. Howard and Bray (1988) found that the desire to get ahead was one of the most powerful predictors of advancement in their longitudinal study of AT\&T managers. Since people use their aspirations (goals) as standards of self-satisfaction (Bandura, 1986), it means that people with high goals should be harder to satisfy than people with low goals (Mento, Locke, \& Klein, in press). This suggests that high ambition, since it represents a high standard of aspiration, should be associated with low satisfaction. Ambitious people are those who are not satisfied with where they are now in the organizational hierarchy. Thus, ambition is hypothesized to negatively influence job satisfaction. 


\section{Method}

\section{Setting and Subjects}

The setting for this research was a large Northeastern University. Subjects, members of the clerical profession, were sampled from all departments within the university. Sixty-one percent of respondents worked in academic (versus nonacademic) departments. Education of the respondents ranged from high school diploma (32\%) to college degree $(15 \%)$. The average annual salary was $\$ 19,045$ (SD $=\$ 6,293)$, with a range of $\$ 9,840$ to $\$ 37,032$. Sixty-four percent of the respondents were married. Age ranged from 19 to 69 years, with an average age of 37.7 years $(\underline{S D}=10.9$ years). Average hours worked per week were 39.1 ( $\underline{\mathrm{SD}}=3.2$ hours). Professional experience ranged from newly employed to 40 years, with a mean of 8.8 years $(\underline{\mathrm{SD}}=7.0$ years $)$. Eighty-seven percent of the respondents were female and $96 \%$ were white.

\section{Measures}

Multiple measurements of all core constructs were used to generate more reliable estimates. Since the relations of interest in this study were psychological in nature, selfreport data were considered an essential source of information on the key constructs of interest. However, in an attempt to remove the possibility that the relations observed were due to self-report bias, the focal employee's dysfunctional thought processes and subjective well-being also were evaluated from the perspective of a "significant other" (i.e., a spouse or family member). These significant other reports, in conjunction with self-reports, should yield a more accurate, complete, and unbiased estimate of the focal employee's dysfunctional attitudes and subjective well-being.

Dysfunctional thought processes. Dysfunctional thought processes were measured by the Dysfunctional Attitude Survey (DAS), a 100-item survey that measures dysfunctional cognitions or beliefs (Weissman \& Beck, 1978). The DAS is one of the more widely used and valid measures of cognitive processes (Cane, Olinger, Gotlib, \& Kuiper, 1986; Oliver \& Baumgart, 1985). Individuals are asked to indicate their agreement with statements 
regarding how they think on a 1 (totally disagree) to 7 (totally agree) point scale. Although the 100 items are summed to form an overall measure of dysfunctional thought processes, the DAS contains items measuring several types of dysfunctional thought process. For example, dependence on others is assessed through such questions as, "I cannot find happiness unless I am loved by another person." Perfectionism is measured by questions such as, "A person should do well at everything he or she undertakes." Overgeneralization is measured by questions such as, "If someone performs an inconsiderate act, it means he or she is a bad person." In the present study, the coefficient alpha reliability estimate for the 100-item scale was .93. ${ }^{1}$

Significant others were asked to evaluate how often the focal employee engaged in dysfunctional thought processes. The significant other was asked to indicate how descriptive 18 statements taken from the DAS were of the focal employee. These statements were selected to sample the full range of types of dysfunctional thought processes. The coefficient alpha for this sub-scale was .76.

Job dysfunctional thought processes. Job dysfunctional thought processes were measured by presenting 13 hypothetical scenarios to individuals, and asking them the extent to which the scenario was descriptive of them. Again, an effort was made to sample all dimensions of dysfunctional thought processes as applied to the job. For example, perfectionism on the job was measured by the following question:

Blue made an error on an important piece of work, although no great disaster occurred as a result and the error was eventually corrected. Blue concluded that there was no excuse for the mistake, and that the error was unforgivable. People should not make mistakes at work, Blue thought. These 13 items were summed to form an overall scale. The coefficient alpha for this scale was .70 .

The significant other was asked to indicate how descriptive 5 scenarios describing job dysfunctional cognitions were of the focal employee. The scenarios were taken from 
the 13 items on the focal employee survey. The coefficient alpha reliability estimate for this 5-item scale was .65 .

Subjective well-being. Subjective well-being was measured using several instruments. Self-reported subjective well-being was measured with six instruments, four of which also were completed by the significant other. The four sub-scales that were completed by both the focal employee and significant other were: 1) a modified version of the Affects Balance Scale (see Diener, 1984), a list of 22 adjectives describing hedonic states (e.g., nervous, sad, elated, delighted) (coefficient alpha, self-report $=.94$; coefficient alpha, significant other report $=.94) ; 2$ ) the "percent time happy" item (Fordyce, 1977), which Diener (1984) concluded to have high validity as a single-item measure; 3) a modified version of Underwood and Froming's (1980) measure, which contained 9 items with which the respondent is asked to indicate their agreement (e.g., "I am usually quite cheerful;" coefficient alpha, self-report = .92; coefficient alpha, significant other report = $.91)$; 4) the Satisfaction with Life Scale (Diener, Emmons, Larsen, \& Griffin, 1985), a fiveitem measure of life satisfaction consisting of such statements as, "In most ways my life is close to ideal" (coefficient alpha, self-report $=.86$; coefficient alpha, significant other report $=.88)$.

Additionally, focal employees completed the PANAS scales (Watson, Clark, \& Tellegen, 1988), which assess both positive affect and negative affect by asking the respondents to indicate how often they generally experience ten positive and ten negative emotions (e.g., upset, proud, ashamed, inspired). Diener (1990) has argued that positive and negative affectivity are best thought of as measurements of subjective well-being, since evidence indicates they are not completely independent, totally stable, and they correlate highly with other measures of subjective well-being. The coefficient alpha for the positive affect sub-scale was .87 . The coefficient alpha for the negative affect sub-scale was .89 . Using all six measures of subjective well-being assessed from two sources should yield a valid measure of the construct. 
Job satisfaction. Job satisfaction was measured by the Job Descriptive Index (JDI; Smith et al., 1969), as modified by Roznowski (1989). The five facets of job satisfaction measured by the JDI are (coefficient alpha reliability estimates are in parentheses): pay ( $\alpha$ $=.87$ ), promotion $(\alpha=.88)$, supervision $(\alpha=.89)$, co-workers $(\alpha=.89)$, and the work itself $(\alpha=.88)$. The intercorrelations of those facets reveal a communality among the dimensions, suggesting a second-order general factor (Judge \& Hulin, in press; Parsons \& Hulin, 1982) that represents overall job satisfaction.

Affective disposition. Affective disposition was measured by what is termed the Neutral Objects Satisfaction Questionnaire, based on Weitz's (1952) survey. The survey measures affective disposition by assessing how satisfied the respondent is with a list of mostly neutral objects common to everyday life (e.g., telephone service, restaurant food, popular music). Individuals highly satisfied with the objects as a whole may have a tendency to see most things (including themselves and their lives) in a favorable light. The obverse is true as well. Weitz's (1952) scale was modified in several ways described by Judge (1990). Results by Judge and Hulin (in press) suggest that the survey is a valid measure of affective disposition. In the present study, the coefficient alpha for the scale was .69.

Work role inputs and outcomes. Work role inputs (education, hours worked), outcomes (pay, intrinsic factors), time to find a job of comparable pay (assessed on a $1=\mathbf{a}$ day or two to $4=$ more than a year scale), and present wage compared to past wages (assessed on a $1=$ present wage is much lower to $5=$ present wage is much higher scale) from the Hulin et al. (1985) model were assessed with specific questions in the focal employee survey. The information on intrinsic job characteristics was obtained by a fiveitem version of the Job Diagnostic Survey (Hackman \& Oldham, 1980). Although the possibility exists that assessments of intrinsic job characteristics are influenced by workers' level of job satisfaction (Roberts \& Glick, 1981), this may be the best information on intrinsic factors available. 
Ambition. Ambition was assessed by a question on the survey that asked the individual how many levels they wished to move up from their present job. Individuals who express a desire to move up many levels are assumed to have more ambition than those who are content where they are at. The mode response was a desire to move up 2 levels from the present position.

Job and work avoidance. Consistent with Hanisch and Hulin (1991) and Roznowski et al. (1991), job avoidance was measured by asking the individual to objectively report the likelihood of engaging in the following 6 behaviors within the next year (rated on a $1=$ very unlikely to 5 = very likely scale): absent, tardy, miss meetings, chat with co-workers about non-work issues, quit, and give less than $100 \%$ on the job (shirk). These items were summed to form a job and work avoidance scale. The coefficient alpha for this scale was .70 .

Demographic information. Age, gender, marital status, race, and whether the individual had been through the EAP program were assessed through individual questions on the focal employee survey.

Procedure

Before surveys were mailed to the focal employees, a stratified random sample was drawn from the approximately 2,000 clericals working at the university. The sample was stratified by college and department to assure that significant breadth in survey responses was obtained. The sampling procedure produced a list of 479 names and campus addresses. Surveys were mailed to employees through campus mail. Subjects were told in a cover letter that individual responses were completely confidential, and were promised their choice of a $\$ 10$ honorarium, a 50-50 chance of winning $\$ 20$, or a 1-in-5 chance of winning $\$ 50$, in return for their participation. Subjects also were asked to sign an informed consent form. Twenty-six surveys were returned as undeliverable. Thus, from a potential pool of 453 respondents, 231 usable surveys were returned, representing a response rate of 
51\%. Response rates did not significantly differ among the departments or between men and women.

As indicated earlier, a "significant other" (e.g., spouse or family member) was asked to complete an evaluation of focal employee dysfunctional thought processes and subjective well-being. Focal employees were informed that their honorarium would be paid only upon return of both self-report and significant other surveys. These dual sources of information about dysfunctional thought processes and subjective well-being should minimize social desirability, halo, and response set tendencies, and increase the relevant heterogeneity of the measures (Roznowski \& Hanisch, 1990). Two-hundred and seventeen usable significant other surveys were returned, indicating that for $94 \%$ of the individuals who returned the focal employee survey, a significant other survey also was returned. Therefore, both self-report and significant other data were available on 217 employees. No significant differences in respondent characteristics (e.g., age, race, sex, salary) were found between those who had a significant other survey returned and those who had not.

Covariance Structure Model

Covariance structure models, estimated in the present study with LISREL 7 (Joreskog \& Sorbom, 1989), allow the joint specification and estimation of the measurement model (e.g., the loadings of the measures on their hypothesized constructs represented in Figure 1) and structural model (e.g., the relationships among the constructs) hypothesized to account for the observed data (Long, 1983). There are two models tested in this study. The first model is based solely on self-report data. The second model is based on "full data," both self-report and significant other evaluations. The advantage of the self-report only model is that there are fewer parameters to be estimated relative to the sample size. This is an important consideration as the number of estimated parameters relative to sample size is an important determinant of convergence, standard errors, and model fit in covariance structure models (Hayduk, 1987; Idaszak, Bottom, \& Drasgow, 1988). The full data model allows inferences about causal relations without complete 
reliance on self-report data. Comparisons of the models permit inferences about the degree to which relations are based on "true" covariance, or self-report method variance. If there is substantial convergence between the models, the findings in the self-report model can be assumed to represent true content relations and not method determined relations. Because both models possess advantages, each was estimated and the results reported.

The measurement and structural components of each model were estimated separately. This strategy reduces the number of parameters to be estimated simultaneously, an important consideration in estimating complex models such as those estimated in the present study (Anderson \& Gerbing, 1988; Schmitt \& Bedeian, 1982). Burt (1976) has also argued that simultaneous estimation results in interpretational confounding (i.e., inability to diagnose the lack of fit in a covariance structure model). Anderson and Gerbing (1988) noted that interpretational confounding can be minimized by the two-step process of first estimating the measurement model, then estimating the structural model; no constraints are placed on structural parameters when estimating the measurement model.

The most widely used measure of fit is the chi-square statistic. Perhaps the most conventional use of chi-square is to examine the ratio of chi-square relative to the degrees of freedom (Hoetler, 1983; La Du \& Tanaka, 1989). Other conventional fit statistics include the goodness-of-fit index, adjusted goodness-of-fit index, root-mean-squareresidual, and coefficient of determination $\left(\underline{R}^{2}\right)$. It is important to note several limitations in interpreting fit statistics. First, a particular value of a fit statistic cannot be used to rule out the possibility of omitted variables. It is possible, albeit less likely, to infer based on examination of the fit statistics that a particular model fits the data well when in fact not all relevant causes of a dependent variable have been specified (La Du \& Tanaka, 1989). Second, levels of most fit statistics depend on the sample size (La Du \& Tanaka, 1989). Finally, since the underlying distributions of most fit statistics are unknown, evaluating their acceptability is subjective. It is best to interpret the acceptability of a particular 
model by examining the fit indices cumulatively (Harris \& Schaubroeck, 1990; James \& James, 1989).

\section{Results}

Correlations served as input for the LISREL model. Using sample covariances as input yielded equivalent results. The correlation matrix for all variables used in the analyses is reported in Table 1.

\section{Insert Table 1 About Here}

\section{Self-report Measurement Model}

Cumulative examination of the fit indices for the self-report measurement model suggest that the hypothesized measurement model provides an adequate fit to the data (chi-square $=73.04$ with 41 degrees of freedom; chi-square/degrees of freedom $=1.78$; goodness-of-fit index $=.95$; adjusted goodness-of-fit index $=.92$; root-mean-square residual $=.05 ; \underline{\mathrm{R}}^{2}=.97$ ). The parameter estimates (factor loadings) of the measures on their respective constructs were strong (average loading $=.66$ ) and significant $(p<.01)$. This suggests that the hypothesized measures adequately represent their underlying constructs. In LISREL, the factor loadings serve as weights used in combining the measures to form the overall constructs used in the structural model estimation. Self-report Structural Model

Examination of the fit statistics suggests that the overall structural model fits the data acceptably (chi-square $=494$ with 238 degrees of freedom; chi-square/degrees of freedom $=2.08$; goodness of fit index $=.87$; adjusted goodness of fit index $=.80$; rootmean-square residual $=.06 ; \underline{R}^{2}=.82$ ). Figure 2 displays the parameter estimates and standard errors of the structural model. The hypothesis that dysfunctional thought processes influence subjective well-being was supported by the results. The coefficient estimate indicates that those who think dysfunctionally are more likely to be unhappy. The 
hypothesis that subjective well-being significantly influences job satisfaction also was supported by the data. Those happy with their lives were more likely to be satisfied with their jobs, controlling for other factors influencing job satisfaction. The reciprocal coefficient from job satisfaction to subjective well-being also was significant. Figure 2 also indicates that job dysfunctional thought processes significantly influenced job satisfaction. Those who think dysfunctionally in terms of their job are less likely to report being satisfied with their jobs. Job satisfaction significantly influenced job avoidance. Those who were dissatisfied with their jobs were more likely to report that they would engage in withdrawal/avoidance behaviors in the future.

Insert Figure 2 About Here

Figure 2 also presents results from the remaining links in the causal model. Affective disposition significantly influenced subjective well-being. As expected, dysfunctional thought processes significantly influenced job dysfunctional thought processes. Individuals who were married reported significantly higher levels of subjective well-being. Contrary to expectations, whites reported lower levels of subjective well-being than minorities. The paths from age, whether the respondent had been through the EAP, and sex to subjective well-being were not significant.

Salary level significantly influenced job satisfaction. Present wage compared to past also exerted a significant $(\mathfrak{p}<.10)$ positive effect on job satisfaction. Intrinsic factors strongly influenced job satisfaction. Ambition, as hypothesized, significantly negatively influenced job satisfaction. Paths from education, hours worked per week, and time to find a job of comparable pay to job satisfaction were not significant.

Several indirect effects were revealed by the model. Indirect effects refer to the effect of one variable on another as mediated through a third variable (Hayduk, 1987). The metric of indirect effects, when a standardized solution is obtained, ranges in absolute 
value from 0 (no effect) to 1 (complete determination). Standard error estimates for indirect and total effects recently have been incorporated into the LISREL program, allowing indirect and total effects to be tested for significance. Dysfunctional thought processes displayed a significant indirect effect on job satisfaction $(-.21 ; \mathfrak{p}<.01)$ through their effect on subjective well-being. Dysfunctional thought processes also exerted a significant indirect effect on job avoidance $(.09 ; \mathrm{p}<.01)$ through their effect on job satisfaction.

\section{Measurement Model Using Self-Report and Significant Other Data}

The intercorrelations between the self and significant other reports were significant $(p<.01)$. The correlations between self and significant other reports of the following variables, corrected for unreliability where appropriate, were as follows: Satisfaction with Life Scale $=.52 ;$ Affects Balance Scale $=.47 ;$ Underwood and Froming scale $=.54$; Fordyce percent happy item $=.39 ; \mathrm{DAS}=.34 ;$ job dysfunctional attitudes scale $=.27$.

It was thought that covariation among the self reports and among the significant other reports of dysfunctional thought processes and subjective well-being was likely to be greater than covariation between the self and significant other reports of the same scale. For example, although no means were significantly different between the self-report and significant other reports of the same scales, it seemed likely that when significant others evaluated the focal employees' subjective well-being using one scale, beliefs regarding the focal employees' subjective well-being were likely to be reflected in their responses to other scales. In recognition of differences between self and significant-other reports, a source factor was hypothesized where evaluations of the significant other loaded both on the source factor and on the subjective well-being construct. Examination of the intercorrelations between the self and significant other reports supported this belief, as the correlations among significant other scales and among self-report scales were higher (e.g., the corrected correlation between significant others' reports of the Underwood and Froming Scale and the Satisfaction with Life Scale was .71) than between significant other 
and self-reports of the same scales (e.g., the corrected correlation between significant other and self-report of the Satisfaction with Life Scale was .52).

The fit statistics of the full data measurement model (chi-square $=240.14$ with 139 degrees of freedom; chi-square/degrees of freedom $=1.73$; goodness of fit index $=.90$; adjusted goodness of fit index $=.86$; root-mean-square residual $=.05 ; \underline{\mathrm{R}}^{2}=.99$ ) indicated that the measurement model fit the data within normally acceptable limits. Table 2 presents the parameter estimates for the full data measurement model. The factor loadings from the combined self-report and significant other estimation are very similar to the loadings estimated in the self-report only model. The loadings of the significant other scales are somewhat lower than the self-report scale loadings. However, all loadings are statistically significant $(\mathrm{p}<.01)$. As in the self-report only model, the factor loadings reported in Table 2 served as factor weights used in combining the self-report and significant other measures to form the overall constructs.

\section{Insert Table 2 About Here}

\section{Structural Model Using Self-Report and Significant Other Data}

The results from estimation of the full data structural model are shown in Figure 3. The fit statistics of the full data structural model were as follows: chi-square $=778.47$ with 428 degrees of freedom; chi-square/degrees of freedom $=1.82$; goodness of fit index $=$ .83 ; adjusted goodness of fit index $=.77$; root-mean-square residual $=.07 ; \underline{R}^{2}=.67$. The lower goodness-of-fit and adjusted goodness-of-fit indices in the full data model are probably a function of the smaller sample size relative to the number of parameters estimated. La Du and Tanaka (1989) have shown that both goodness-of-fit and adjusted goodness-of-fit indices become smaller as the sample size decreases. 


\section{Insert Figure 3 About Here}

The results in Figure 3 indicate some differences from the self-report model. Specifically, the nonrecursive relationship between job satisfaction and subjective wellbeing grows considerably weaker with the introduction of significant other data. However, the effects are still statistically significant. Interestingly, the effect of dysfunctional thought processes on subjective well-being with the full data model was somewhat stronger than that obtained from the estimation using only self-report data. Likewise, the effect of job dysfunctional attitudes on job satisfaction using both self-report and significant other data was consistent with the estimation based on self-report only data, although somewhat stronger in magnitude. Figure 3 also presents results from the remaining links in the causal model. The results are quite consistent with the self-report only data, with the exceptions that in the full data model the effect of hours worked on job satisfaction reaches statistical significance, the effect of present wage compared to past wages on job satisfaction increases in significance, and having been through an EAP exerts a marginally significant effect on subjective well-being, although not in the predicted direction.

The indirect effects from the full data model also were consistent with the selfreport model. Specifically, dysfunctional thought processes displayed a significant indirect effect on job satisfaction that was statistically significant $(-.27 ; \mathrm{p}<.01)$ through their effect on subjective well-being. Dysfunctional thought processes also exerted a significant indirect effect on job avoidance $(.11 ; \mathrm{p}<.01)$ through their effect on job satisfaction.

Based on these results, we can conclude with a reasonable degree of confidence that subjective well-being and job satisfaction significantly influence one another (the exact strength of that effect is open to question, however). Further, we can conclude that dysfunctional thought processes significantly influence subjective well-being directly, and 
job satisfaction and job avoidance indirectly. Finally, job dysfunctional thought processes appear to significantly influence job satisfaction.

The relations observed between the concepts were argued to represent structural relationships between distinct concepts. The plausibility of this argument, however, depends on the assumption that these are valid concepts -- that dysfunctional thought processes, job dysfunctional thought processes, and subjective well-being are not simply alternative measures of an overall affective experience. If in fact they are, it would undermine the causal attributions suggested in this study.

Consequently, the construct validity of the hypothesized constructs was investigated. Construct validity has typically been established through a combination of convergent and discriminant validity (Campbell \& Fiske, 1959; Schwab, 1980). Convergent validities of the constructs were established earlier, by the overall fit and measurement loadings of the hypothesized measurement model (see Table 2). Discriminant validity between the measures was investigated in a manner similar to Brooke, Russell, and Price (1988) and Mathieu and Farr (1991). The fit of the hypothesized measurement model was compared to the fit of a model with one general affective concept consisting of dysfunctional thought processes, job dysfunctional thought processes, and subjective well-being. If the measures do not have adequate discriminant validity, the fit of a single factor model will not be significantly worse than the hypothesized multiple factor model. In such a case, a single factor model would do an acceptable job of describing the data, and measurement relations between the variables may have been misinterpreted as structural relations.

Using 10 randomly sampled items from the DAS, 10 randomly sampled items from the job dysfunctional attitude scale, and 10 randomly sampled items from the subjective well-being scales, with the self-report data, the single factor model provided a significantly worse fit to the data than the hypothesized model (difference in chi square $=171.34$ with 3 degrees of freedom, $\mathrm{p}<.01$ ). Considering also the significant other data, a single factor model also provided a significantly worse fit to the data than the hypothesized model 
(difference in chi square $=136.57$ with 3 degrees of freedom, $\mathrm{p}<.01$ ). Overall, this evidence suggests the factors, as assessed, are empirically distinct. Even forming the DAS and the job dysfunctional attitude scale resulted in a significant decrease in fit $(\mathrm{p}<.01)$.

\section{Discussion}

The main purpose of this study was to determine whether or not dysfunctional thoughts affected subjective well-being and job satisfaction. Within the limitations imposed by the correlational method employed, the results strongly supported the predictions. To the degree people believe that they must be dependent on others for self-worth, believe that they must be perfect in terms of task mastery and not making mistakes, and overgeneralize from a single event to a grand conclusion, they decrease the chances they will enjoy their jobs and their lives in general. It is impressive that theoretical ideas and findings from a totally different domain (the cognitive theory of depression from clinical psychology) were found to have strong relevance to organizational psychology and measurement. Yet this result should not be surprising in that depression is a state of extreme negative affect. Depressed people believe that they are no good, life is no good, and that things will never change for the better. Such a triad (Beck et al., 1979) of selfdefeating conclusions virtually guarantees negative affect with respect to every key aspect of one's life.

From a microanalytic perspective one might ask by what means the dysfunctional thoughts of the type measured by the DAS affect satisfaction. Locke (1976) argued that satisfaction with the job and each job component thereof results from automatic, subconscious appraisals based on three elements: what is perceived (how much is there); what is wanted (how much one believes there should be); and the importance of the element. For exploratory purposes we asked the respondents in this study to rate a few of the Hackman - Oldham (1980) job attributes (e.g., autonomy, variety, task significance) on each of the three dimensions suggested by Locke (1976). We found that the DAS scale (as well as the job DAS scale) was most frequently and negatively correlated with ratings of the 
amount perceived. Thus, subjects high on the DAS scales saw their jobs as having less autonomy, variety, and significance than those low on the DAS scores. There also was a tendency for those high on the DAS scales to see the job elements as more important than those with low DAS scores. The combination of perceiving the job as offering a low amount of a characteristic and placing high importance on getting it would certainly be consistent with the lower degree of satisfaction experienced by those with high DAS scores (DAS scores were not correlated with amount wanted). These preliminary results suggest that dysfunctional thinking may have both an external and internal aspect. Externally, dysfunctional thinkers may see less of what is there and internally may place more importance on getting it than non-dysfunctional thinkers. Clearly these results are only preliminary, but they suggest that further microanalytic studies of the mechanisms by which dysfunctional thoughts affect attitudes are warranted.

It should not be assumed, however, that dysfunctional thinking is the only category of dispositional factors that could affect subjective well-being and job satisfaction. Other possibilities are self-esteem (which itself is affected by thinking -- see below), locus of control, self-efficacy, intelligence, and ambition. Ambition was measured with a one-item scale on an exploratory basis in the present study and was found, as predicted, to be negatively related to satisfaction with the job. People who are ambitious are, necessarily, dissatisfied with where they are now as a permanent state and want to improve the conditions of their job (e.g., responsibility, job level, pay) in some significant aspect. Because such people have higher standards for self-satisfaction, they must achieve more in order to be satisfied (Mento et al., in press) than do people with less ambition. This is what drives them to excel and improve (Howard \& Bray, 1988). Further studies of ambition and other dispositional factors, would, then, seem warranted.

Some discussion is needed concerning the observed relationship between job satisfaction and subjective well-being. An obvious reason for job satisfaction playing a causal role in subjective well-being is that it represents a part - whole relationship - that is, 
the job is a part of life and thus is taken into account when rating subjective well-being (in the same way that satisfaction with work is taken into account when rating overall job satisfaction) (Locke, 1976). One prediction that would follow from this is that the job satisfaction - subjective well-being relationship should be moderated by the degree to which the job is considered an important part of one's life. In fact, some past research supports this prediction (Iris \& Barrett, 1972; Rice et al., 1985; Steiner \& Truxillo, 1987). Going the other direction, subjective well-being could affect job satisfaction through a spillover effect, that is, emotional generalization from one domain to the other. For example, if one's married and family life were exceptionally happy, one might go to work in a positive mood and interpret events on the job in a benevolent and positive light (George, 1989). The opposite could occur if one went to the job in a bad mood due to an unhappy family situation. This explanation is consistent with cognitive models of attitude formation, where happy individuals may tend to store, evaluate, or recall information related to their job differently from unhappy individuals (Isen \& Baron, 1991; Motowidlo \& Lawton, 1984; Porac, 1987). Other relationships, of course, are possible as well (e.g. compartmentalization, compensation), but these would not predict a positive correlation between domains.

It is also important to note the magnitude of the relationship between subjective well-being and job satisfaction varied between the self-report only model and the model estimated with both self-report and significant other data. It is possible that the full data model is more accurate because the relationships are less affected by self-report bias. On the other hand, it is also possible that the relationship declined because significant others are less knowledgeable about the well-being of the focal employee. We cannot test these competing explanations, but it does reinforce the importance of collecting information from more than one source. It should also be noted that introduction of the significant other data had little effect on the influence of dysfunctional thought processes on subjective 
well-being and job satisfaction. Thus, a higher degree of confidence can be placed in the exact magnitude of these specific effects, which were fairly substantial.

Explaining the relationship between affective disposition and subjective well-being is slightly more problematic. On the one hand, people inclined to be positive in general should be more positive about life but this is almost a tautology. One could just as well say that people who are happy in life will be positive with respect to even neutral objects like 8 $1 / 2^{\prime \prime} \times 11^{\prime \prime}$ paper and their telephone number. However, it should be noted that all items in the affective disposition scale were not as neutral as the two examples above.

Two of the items in this scale asked subjects to rate their degree of satisfaction with "yourself" and "the way you were raised." Few people are neutral (as compared to $81 / 2$ " x 11" paper) about such issues. The sum of these two "ego" items correlated more highly with other key variables in our model than did the total of the remaining items in the neutral objects scale. For example, the ego scale correlated .58 with subjective well-being (versus .23 for the remainder scale), -.32 with dysfunctional attitudes (versus -.05 , ns, for the remainder scale), -.33 with job dysfunctional attitudes (versus -.17 for the remainder scale), and -.33 with job avoidance (versus $-.12, \underline{\text { ns, }}$, for the remainder scale). These results have intriguing implications. If our ego measure can be considered to be a crude measure of self-esteem, it suggests that people who like themselves are more likely to enjoy their lives and work than those who do not like themselves. In fact, this has been observed in previous studies (Brockner, 1988). One reason for this association might be that people who think rationally are more likely to have high self-esteem than people who think irrationally, as shown by the negative correlation between the dysfunctional attitude scales and our ego measure noted above. From a causal perspective, most fundamentally, rational thinking should lead both to higher self-esteem and to greater happiness in the job and life (Rand, 1961). These issues, including that of reciprocal causality, are clearly worthy of further study. 
A strength of the present study is that data were collected from two sources. Most of the past research in this area has relied on only self-reports, making it possible that selfreport variance biased the relationships. Although the present study improves upon that practice, our results may not be completely independent of self-report bias since selfreports were a primary means through which the measurements were formed. In order to remove this possibility, it would be possible to estimate a model with exclusively significant other reports on certain concepts (e.g., subjective well-being, dysfunctional attitudes). However, this would not be an appropriate test. Since the focal employees probably know their own affective states and thought processes better than anyone else, discarding this information in a model estimation would yield a poorer measurement of the concepts. Therefore, while we feel a contribution of our paper is that significant other reports were used, we would not go so far as to say they should be relied upon to the exclusion of selfreport data.

The practical implications of this study are worth noting. Dispositional researchers have often argued that organizations may want to select workers based on disposition because of the potential impact it has on job satisfaction and related behaviors (Arvey et al., 1989; Pulakos \& Schmitt, 1983; Staw \& Ross, 1985; Staw et al., 1986). However, the results of the present study suggest a different alternative: employee well-being and job satisfaction may be increased by reducing the degree to which employees think dysfunctionally about their jobs and lives in general. This speculation is consistent with previous research suggesting that reducing dysfunctional attitudes produces positive benefits. For example, Kovacs, Rush, Beck, and Hollon (1981) found that most individuals realized a dramatic and long-lasting increase in overall affect after several weeks of regular cognitive therapy sessions. Another study suggested that cognitive therapy are an important component of EAPs (Klarriech, DiGiuseppe, \& DiMattia, 1987). Finally, cognitive therapy has been found to reduce coronary prone behavior (Levenkron, Cohen, Mueller, \& Fisher, 1983) which also has cost-saving implications for organizations. Thus, 
the practical implications of the dispositional approach to job satisfaction are not confined to the selection process. The results of this study imply that organizational interventions aimed at increasing employee well-being, and thus job satisfaction, may be effective and well-advised.

On a related note, the present study has implications for future dispositional research. There is strong evidence that dispositional constructs matter in judgments of job satisfaction. However, there remains a need to employ theoretical concepts that may help in understanding the psychology behind the effect of disposition on job attitudes (Judge, in press; Weiss, 1991). The present study represented a successful effort in that regard by applying the cognitive theory of depression. Our intriguing findings for the ego measure suggest the relevance of cognitive-ego psychology (Packer, 1985, 1986) for understanding job satisfaction. More efforts along these lines are needed. As suggested earlier, past work from cognitive psychology may be of great import here.

With respect to the remaining relationships in the model, there were few surprises. The negative relationship between job satisfaction and job avoidance and the relationship between intrinsic job characteristics and job satisfaction replicates similar findings in many studies. The salary results were also expected as was the result for marital status. Race came out in the opposite direction expected and several other factors showed weak or nonsignificant effects. These results are in line with other studies that show demographic characteristics are less strongly related to job attitudes than are direct appraisals of the job situation. The most interesting implication of our results is that such appraisals may be affected by dispositional factors such as how people think. 


\section{References}

Ajzen, I. (1991). The theory of planned behavior. Organizational Behavior and Human Decision Processes, 50, 179-211.

Anderson, J.C., \& Gerbing, D.W. (1988). Structural equation modeling in practice: A review and recommended two-step approach. Psychological Bulletin, 103, 411-423. Andrews, F.M., \& Withey, S.B. (1976). Social indicators of well-being: America's perception of life quality. New York: Plenum Press.

Arvey, R.D., Bouchard, T.J., Segal, N.L., \& Abraham, L.M. (1989). Job satisfaction: Environmental and genetic components. Journal of Applied Psychology, 74, 187192.

Bandura, A. (1986). Social foundations of thought and action: A social-cognitive theory. Englewood Cliffs, NJ: Prentice Hall.

Bargh, J.A., \& Tota, M.E. (1988). Context-dependent automatic processing in depression: Accessibility of negative constructs with regard to self but not others. Journal of Personality and Social Psychology, 54, 925-939.

Beck, A.T. (1963). Thinking and depression: Idiosyncratic content and cognitive distortions. Archives of General Psychiatry, 9, 324-333.

Beck, A.T. (1967). Depression: Causes and treatment. Philadelphia: University of Pennsylvania Press.

Beck, A.T. (1987). Cognitive models of depression. Journal of Cognitive Psychotherapy, 1, 5-37.

Beck, A.T., Rush, A.J., Shaw, B.F., \& Emery, G. (1979). Cognitive theory of depression. New York: Guilford Press.

Beehr, T.A., \& Gupta, N. (1978). A note on the structure of employee withdrawal. Organizational Behavior and Human Performance, 21, 73-79.

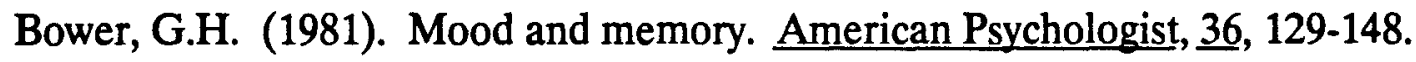


Brief, A.P., Burke, M.J., George, J.M., Robinson, B., \& Webster, J. (1988). Should negative affectivity remain an unmeasured variable in the study of job stress? Journal of Applied Psychology, 73, 193-198.

Brockner, J. (1988). Self-esteem at work. Lexington, MA: Lexington Books.

Brooke, P.P., Russell, D.W., \& Price, J.L. (1988). Discriminant validation of measures of job satisfaction, job involvement, and organizational commitment. Journal of Applied Psychology, 73, 139-145.

Burt, R.S. (1976). Interpretational confounding of unobserved variables in structural equation models. Sociological Methods and Research, 5, 3-51.

Campbell, D.T., \& Fiske, D.W. (1959). Convergent and discriminant validity by the multitrait-multimethod matrix. Psychological Bulletin, 56, 81-105.

Cane, D.B., Olinger, L.J., Gotlib, I.H., \& Kuiper, N.A. (1986). Factor structure of the Dysfunctional Attitude Scale in a student population. Journal of Clinical Psychology, 42, 307-309.

Crandell, C.J., \& Chambless, D.L. (1986). The validation of an inventory for measuring depressive thoughts: The Crandell Cognitions Inventory. Behavior Research and Therapy, 24, 403-411.

Davis-Blake, A., \& Pfeffer, J. (1989). Just a mirage: The search for dispositional effects in organizational research. Academy of Management Review, 14, 385-400.

Diener, E. (1984). Subjective well-being. Psychological Bulletin, 95, 542-575.

Diener, E. (1990). Challenges in measuring subjective well-being and ill-being. Manuscript submitted for publication.

Diener, E., Emmons, R.A., Larsen, R.J., \& Griffin, S. (1985). The satisfaction with life scale. Journal of Personality Assessment, 49, 71-75.

Dobson, K.S. (1989). A meta-analysis of the efficacy of cognitive therapy for depression. Journal of Consulting and Clinical Psychology, 57, 414-419. 
Dobson, K.S., \& Shaw, B.F. (1986). Cognitive assessment with major depressive disorders. Cognitive Therapy and Research, 10, 13-29.

Fishbein, M., \& Ajzen, I. (1975). Belief, attitude, intentions, and behavior: An introduction to theory and research. Boston: Addison-Wesley.

Fisher, C., \& Locke, E.A. (in press). The new look in job satisfaction theory and research. In J. Cranny, P. Smith, \& E.F. Stone (Eds.), Job satisfaction: Advances in theory and research. New York: Macmillan.

Fordyce, M.W. (1977). Development of a program to increase personal happiness. Journal of Counseling Psychology, 24, 511-521.

George, J.M. (1989). Mood and absence. Journal of Applied Psychology, 74, 317-324.

Gerhart, B. (1987). How important are dispositional factors as determinants of job satisfaction? Implications for job design and other personnel programs. Journal of Applied Psychology, 72, 366-373.

Gerhart, B. (1990). The doubtful practical relevance of dispositional effects on job satisfaction. Paper presented at the annual meetings of the Academy of Management. San Francisco, CA.

Haaga, D.A.F., Dyck, M.J., \& Ernst, D. (1991). Empirical status of cognitive theory of depression. Psychological Bulletin, 110, 215-236.

Hackman, J.R., \& Oldham, G.R. (1980). Work redesign. Reading, MA: Addison-Wesley. Hanisch, K.A., \& Hulin, C.L. (1991). General attitudes and organizational withdrawal: An evaluation of a causal model. Journal of Vocational Behavior, $\underline{39}, 110-128$.

Harris, M.M., \& Schaubroeck, J. (1990). Confirmatory modeling in organizational behavior/human resource management: Issues and applications. Journal of Management, 16, 337-360.

Hayduk, L.A. (1987). Structural equation modeling with LISREL: Essentials and advances. Baltimore: John Hopkins. 
Hoetler, J.W. (1983). The analysis of covariance structures: Goodness-of-fit indices. Social Methods and Research, 11, 325-344.

Howard, A., \& Bray, D. (1988). Managerial lives in transition: Advancing age and changing times. New York: Guilford Press.

Hulin, C.L. (1991). Adaptation, persistence, and commitment in organizations. In M.D. Dunnette \& L.M. Hough (Eds.), Handbook of industrial and organizational psychology (2nd ed., Vol. 2, pp. 445-505). Palo Alto, CA: Consulting Psychologist Press.

Hulin, C.L., Roznowski, M., \& Hachiya, D. (1985). Alternative opportunities and withdrawal decisions: Empirical and theoretical discrepancies and an integration. Psychological Bulletin, 97, 233-250.

Idaszak, J.R., Bottom, W.P., \& Drasgow, F. (1988). A test of the measurement equivalence of revised Job Diagnostic Survey: Past problems and current solutions. Journal of Applied Psychology, 73, 647-656.

Ingram, R.E. (1990). Self-focused attention in clinical disorders: Review and a conceptual model. Psychological Bulletin, 107, 156-176.

Iris, B., \& Barrett, G.V. (1972). Some relations between job and life satisfaction and job importance. Journal of Applied Psychology, 56, 301-304.

Isen, A.M., \& Baron, R.A. (1991). Positive affect as a factor in organizational behavior. In L.L. Cummings \& B.M. Staw (Eds.), Research in organizational behavior, (Vol. 13, pp. 1-53). Greenwich, CT: JAI Press.

James, L.A., \& James, L.R. (1989). Causal modeling in organizational research. In C. Cooper \& I. Robertson (Eds.), International review of industrial and organizational psychology (pp. 371-404). New York: Wiley.

James, L.R., Mulaik, S.A., \& Brett, J.M. (1982). Causal analysis: Assumptions, models, and data. Beverly Hills: Sage. 
Joreskog, K.G., \& Sorbom, D. (1989). LISREL 7: A guide to the program and applications. Chicago: SPSS Inc.

Judge, T.A. (1990). Job satisfaction as a reflection of disposition: Investigating the relationship and its effect on employee adaptive behaviors. Unpublished doctoral dissertation, University of Illinois at Urbana-Champaign.

Judge, T.A. (in press). The dispositional perspective in human resources research. In G.R. Ferris \& K.M. Rowland (Eds.), Research in personnel and human resources management (Vol. 10). Greenwich, CT: JAI Press.

Judge, T.A., \& Hulin, C.L. (in press). Job satisfaction as a reflection of disposition: A multiple source causal analysis. Organizational Behavior and Human Decision Processes.

Keller, K.E. (1983). Dysfunctional attitudes and the cognitive theory for depression. Cognitive Therapy and Research, 7, 437-444.

Klarriech, S., DiGiuseppe, R., \& DiMattia, D. (1987). Dispelling the "uniformity myth" in EAP's. Professional Psychology, 18, 140-144.

Kovacs, M., Rush, A.J., Beck, A.T., \& Hollon, D. (1981). Depressed outpatients treated with cognitive therapy or pharmacotherapy. Archives of General Psychiatry, 38, 3339.

Kuiper, N.A., \& Olinger, L.J. (1986). Dysfunctional attitudes and a self-worth contingency model of depression. In P.C. Kendall (Ed.), Advances in cognitive-behavioral research and therapy (Vol. 5, pp. 115-142). New York: Academic Press.

Kuiper, N.A., Olinger, L.J., \& Swallow, S.R. (1987). Dysfunctional attitudes, mild depression, views of self, self-consciousness, and social perceptions. Motivation and Emotion, 11, 379-401.

La Du, T.J., \& Tanaka, J.S. (1989). Influence of sample size, estimation method, and model specification on goodness-of-fit assessments in structural equation models. Journal of Applied Psychology, 74, 625-635. 
Levenkron, J.C., Cohen, J.D., Mueller, H.S., \& Fisher, E.B. (1983). Modifying the Type A coronary-prone behavior pattern. Journal of Consulting and Clinical Psychology, 51, 192-204.

Levin, I., \& Stokes, J.P. (1989). Disposition approach to job satisfaction: Role of negative affectivity. Journal of Applied Psychology, 74, 752-758.

Lewinsohn, P.M., \& Rosenbaum, M. (1987). Recall or parental behavior by acute depressives, remitted depressives, and nondepressives. Journal of Personality and Social Psychology, 52, 611-619.

Locke, E.A. (1976). The nature and causes of job satisfaction. In M.D. Dunnette (Ed.), Handbook of industrial and organizational psychology (Vol. 1, pp. 1297-1343). Chicago: Rand McNally.

Long, J.S. (1983). Covariance structure models: An introduction to LISREL. Beverly Hills: Sage.

Mathieu, J.E., \& Farr, J.L. (1991). Further evidence for the discriminant validity of measures of organizational commitment, job involvement, and job satisfaction. Journal of Applied Psychology, 76, 127-133.

Mento, A.J., Locke, E.A., \& Klein, H. (in press). The relation of personal goal level to valence and instrumentality. Journal of Applied Psychology.

Motowidlo, S.J., \& Lawton, G.W. (1984). Affective and cognitive factors in soldiers' reenlistment decisions. Journal of Applied Psychology, 69, 157-166.

Olinger, L.J., Kuiper, N.A., \& Shaw, B.F. (1987). Dysfunctional attitudes and stressful life events: An interactive model of depression. Cognitive Therapy and Research, 11 , $25-40$.

Oliver, J.M., \& Baumgart, E.P. (1985). The Dysfunctional Attitude Scale: Psychometric properties and relation to depression in an unselected adult population. Cognitive Therapy and Research, 9, 161-167.

Packer, E. (1985). The art of introspection. The Objectivist Forum, 6, 1-10. 
Packer, E. (1986). The art of introspection. The Objectivist Forum, 7, 1-8.

Parsons, C.K., \& Hulin, C.L. (1982). An empirical investigation of item response theory and hierarchical factor analysis in applications to the measurement of job satisfaction. Journal of Applied Psychology, 67, 826-834.

Porac, J.F. (1987). The job satisfaction questionnaire as a cognitive event: First- and second-order processes in affective commentary. In K.M. Rowland \& G.R. Ferris (Eds.), Research in personnel and human resources management (Vol. 5, pp. 51102). Greenwich, CT: JAI Press.

Porter, L.W., \& Steers, R.M. (1973). Organizational, work, and personal factors in

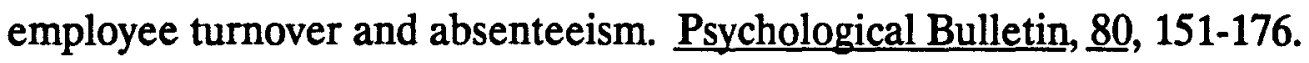

Pulakos, E.D., \& Schmitt, N. (1983). A longitudinal study of a valence model approach for the prediction of job satisfaction of new employees. Journal of Applied Psychology, $68,307-312$.

Ramanathan, C.S. (1990). Employee assistance programs: Past, present, and future. In G.R. Ferris, K.M. Rowland, \& M.R. Buckley (Eds.), Human resource management: Perspectives and issues (2nd ed., pp. 411-418). Boston: Allyn and Bacon.

Rand, A. (1961). The virtue of selfishness. New York: New American Library (Signet).

Rice, R.W., McFarlin, D.B., Hunt, R.G., \& Near, J.P. (1985). Job importance as a moderator of the relationship between job satisfaction and life satisfaction. Basic and Applied Social Psychology, 6, 297-316.

Roberts, K.H., \& Glick, W. (1981). The job characteristics approach to task design: A critical review. Journal of Applied Psychology, 66, 193-217.

Roznowski, M. (1989). An examination of the measurement properties of the job descriptive index with experimental items. Journal of Applied Psychology, 74, 805814.

Roznowski, M., \& Hanisch, K.A. (1990). Building systematic heterogeneity into work attitudes and behavior measures. Journal of Vocational Behavior, $\underline{36}, 361-375$. 
Roznowski, M., Rosse, J.G., \& Miller, H.E. (1991). The scientific value of breath in employee responses: Employee withdrawal, citizenship, job attitudes and perceptions. Working paper, Ohio State University.

Schmitt, N., \& Bedeian, A.G. (1982). A comparison of LISREL and two-stage least squares analysis of a hypothesized life-job satisfaction relationship. Journal of Applied Psychology, 67, 806-817.

Schwab, D.P. (1980). Construct validity in organizational behavior. In B.M. Staw \& L.L. Cummings (Eds.), Research in organizational behavior (Vol. 2, pp. 3-43). Greenwich, CT: JAI.

Smith, P.C., Kendall, L., \& Hulin, C.L. (1969). The measurement of satisfaction in work and retirement. Chicago: Rand McNally.

Smith, T.W., \& Allred, K.D. (1986). Rationality revisited: A reassessment of the empirical support for the rational-emotive model. In P.C. Kendall (Ed.), Advances in cognitive-behavioral research and therapy (Vol. 5, pp. 63-87). New York: Academic Press.

Staw, B.M., \& Ross, J. (1985). Stability in the midst of change: A dispositional approach to job attitudes. Journal of Applied Psychology, 70, 469-480.

Staw, B.M., Bell, N.E., \& Clausen, J.A. (1986). The dispositional approach to job attitudes: A lifetime longitudinal test. Administrative Science Quarterly, 31, 56-77.

Steiner, D.D., \& Truxillo, D.M. (1987). Another look at the job satisfaction - life satisfaction relationship: A test of the disaggregation hypothesis. $\underline{\text { Journal of }}$ Occupational Behavior, $\underline{8}, 71-77$.

Tait, M., Padgett, M.Y., \& Baldwin, T.T. (1989). Job and life satisfaction: A reexamination of the strength of the relationship and gender effects as a function of the date of the study. Journal of Applied Psychology, 74, 502-507.

Underwood, B., \& Froming, W.J. (1980). The mood survey: A personality measure of happy and sad moods. Journal of Personality Assessment, 44, 404-414. 
Watson, D., \& Clark, L.A. (1984). Negative affectivity: The disposition to experience aversive psychological states. Psychological Bulletin, 96, 465-490.

Watson, D., Clark, L.A., \& Tellegen, A. (1988). Development and validation of brief measures of positive and negative affect: The PANAS scales. Journal of Personality and Social Psychology, 54, 1063-1070.

Weiss, H.M. (April, 1991). Discussant comments. In K. James \& R. Cropanzano (Chairs), Dispositions and work outcomes. Symposium conducted at the Sixth Annual Conference of the Society for Industrial and Organizational Psychology, St. Louis, MO.

Weissman, A., \& Beck, A.T. (1978). Development and validation of the Dysfunctional Attitude Scale. Paper presented at the annual convention of the Association for Advancement of Behavior Therapy, Chicago.

Weitz, J. (1952). A neglected concept in the study of job satisfaction. Personnel Psychology, $\underline{5}, 201-205$.

Wenzlaff, R.M., Wegner, D.M., \& Roper, D.W. (1988). Depression and mental control: The resurgence of unwanted negative thoughts. Journal of Personality and Social Psychology, 55, 882-892.

Wierzbicki, M., \& Rexford, L. (1989). Cognitive and behavioral correlates of depression in clinical and nonclinical populations. Journal of Clinical Psychology, 45, 872-877.

Wise, E.H., \& Barnes, D.R. (1986). The relationship among life events, dysfunctional attitudes, and depression. Cognitive Therapy and Research, 10, 257-266.

Youngblood, S.A. (1984). Work, nonwork, and withdrawal. Journal of Applied Psychology, 69, 106-117. 


\begin{abstract}
Author Notes
The authors thank Gerald Thomas for assistance with administration of the study and Shinichiro Watanabe for assistance with data entry. Correspondence regarding this article may be addressed to Timothy A. Judge, Department of Personnel and Human Resource Studies, 393 Ives Hall, Cornell University, Ithaca, New York 14853-3901.
\end{abstract}




\section{Footnote}

${ }^{1}$ We factor analyzed the full DAS and were able to isolate meaningful factors, most of which were interpretable in terms of the theoretical base of the scale within the cognitive theory of depression. However, using separate sub-scales in the analysis did not appreciably change the results (e.g., of the major sub-scales, there were none which were markedly more highly correlated with subjective well-being than the others). Thus, we only used the total scale in our model. 
Table 1

Correlations Between Variables Used in Analyses

Variable

1. Positive Affectivity scale

2. Negative Affectivity Scale

3. Fordyce Percent Happy Item

4. Satisfaction with Life Scale

5. Underwood \& Froming Scale

6. Affects Balance scale

7. JDI - Work Scale

8. JDI - Coworkers Scale

9. JDI - Supervision Scale

10. JDI - Pay Scale

11. JDI - Promotion scale

12. Job Dysfunctional Attitudes

13. Dysfunctional Attitude scale

14. Married

15. White

16. Been Through EAP

17. Age

18. Sex

19. Affective Disposition

20. Salary

21. Present Wage Compared to Past

22. Education

23. Hours Worked per Week

24. Time to Find Comparable Job

25. Intrinsic Factors

26. Ambition

27. Job Avoidance

28. Fordyce Percent Happy Item, soR

$\begin{array}{lllllllllllllll}1 & 2 & 3 & 4 & 5 & 6 & 7 & 8 & 9 & 10 & 11 & 12 & 13 & 14 & 15\end{array}$

29. Satisfaction With life Scale, SOR

30. Underwood \& Froming Scale, soR

31. Affects Balance Scale, SOR

$-\overline{39}--$

$50-64$

$36-48 \quad 61$

$57-70 \quad 83 \quad 54$

$\begin{array}{lllll}57 & -80 & 74 & 58 & -\overline{0}\end{array}$

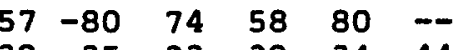

$\begin{array}{lllllll}39 & -35 & 33 & 39 & 34 & 44 & -\end{array}$

$\begin{array}{llllllll}08 & -20 & 20 & 17 & 21 & 26 & 30 & -\end{array}$

$\begin{array}{lllllllll}23 & -32 & 24 & 26 & 20 & 33 & 42 & 20 & -\end{array}$

$\begin{array}{llllllllll}17 & -32 & 27 & 35 & 29 & 31 & 33 & 16 & 27\end{array}$

$\begin{array}{lllllllllll}22 & -24 & 20 & 24 & 24 & 26 & 34 & 14 & 25 & 30 & -\end{array}$

$\begin{array}{lllllllllll}-38 & 49 & -40 & -24 & -47 & -50 & -24 & -18 & -17 & -08 & -12\end{array}$

$\begin{array}{llllllllllll}-24 & 43 & -38 & -19 & -41 & -40 & -19 & -15 & -10 & -16 & -14 & 60\end{array}$

$\begin{array}{llllllllllllll}01 & -14 & 19 & 28 & 15 & 14 & 14 & -01 & 00 & 05 & -06 & -09 & -00 & -\end{array}$

$\begin{array}{lllllllllllllll}-07 & 12 & -06 & -02 & -10 & -06 & -02 & -08 & -03 & -02 & -17 & 01 & -05 & 13 & -\end{array}$

$\begin{array}{llllllllllllllll}-06 & 17 & -07 & -20 & -07 & -19 & -05 & -10 & -06 & -06 & -08 & 06 & -01 & -07 & 08\end{array}$

$\begin{array}{lllllllllllllll}08 & -18 & 05 & 03 & 07 & 08 & 13 & 04 & 09 & 22 & -14 & -01 & -14 & 09 & 10\end{array}$

$\begin{array}{lllllllllllllll}-15 & 11 & -15 & -08 & -14 & -08 & -08 & 02 & -02 & -07 & -10 & 16 & 18 & -03 & -06\end{array}$

$\begin{array}{lllllllllllllll}26 & -28 & 32 & 36 & 27 & 36 & 22 & 19 & 23 & 24 & 08 & -22 & -13 & 02 & -02\end{array}$

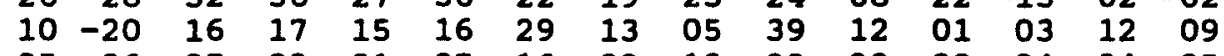

$\begin{array}{lllllllllllllll}-05 & -06 & 07 & 09 & -01 & 07 & 16 & 09 & 13 & 39 & 20 & 08 & 04 & 04 & 05\end{array}$

$\begin{array}{lllllllllllllll}03 & 13 & -10 & 03 & -04 & -11 & -10 & 07 & -02 & -09 & -03 & 02 & 10 & -11 & 08\end{array}$

$\begin{array}{lllllllllllllll}-02 & -06 & 01 & 02 & 08 & 10 & 01 & 05 & -00 & 01 & 08 & -00 & 07 & 08 & 27\end{array}$

$\begin{array}{lllllllllllllll}-12 & 10 & -15 & -08 & -16 & -15 & -02 & 01 & -06 & 11 & -16 & 14 & 14 & 01 & 23\end{array}$

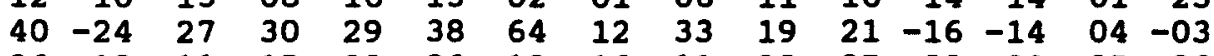

$\begin{array}{lllllllllllllll}06 & 10 & -11 & -15 & -03 & -06 & -19 & -16 & -11 & -28 & -07 & -08 & -02 & -05 & -06\end{array}$

$\begin{array}{lllllllllllllll}-31 & 29 & -21 & -21 & -22 & -33 & -32 & -06 & -20 & -27 & -16 & 23 & 16 & -07 & -12\end{array}$

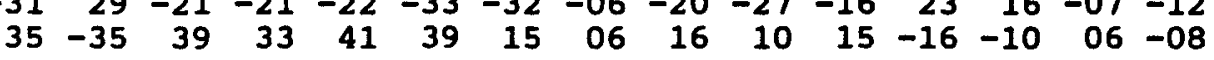

$\begin{array}{lllllllllllllll}21 & -24 & 30 & 45 & 35 & 27 & 21 & 05 & 17 & 24 & 08 & -15 & -11 & 25 & 05\end{array}$

$\begin{array}{lllllllllllllll}32 & -40 & 42 & 36 & 49 & 42 & 11 & 10 & 11 & 11 & 19 & -19 & -15 & 03 & -04\end{array}$

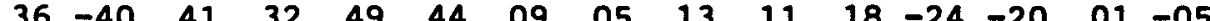

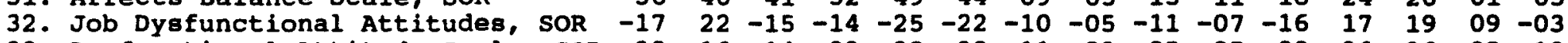

33. Dysfunctional Attitude Scale, SOR $-20 \quad 16-14-09-20-20-11-02-05 \quad 05-0026 \quad 26 \quad 05-13$

Table 1 Continues 
Table 1 (Continued)

Variable $\begin{array}{llllllllllllllllll}16 & 17 & 18 & 19 & 20 & 21 & 22 & 23 & 24 & 25 & 26 & 27 & 28 & 29 & 30 & 31 & 32 & 33\end{array}$

16. Been Through EAP

17. Age

18. Sex

19. Affective Disposition

20. Salary

21. Present Wage Compared to Past

22. Education

23. Hours Worked per Week

24. Time to Find Comparable Job

25. Intrinsic Factors

26. Ambition

27. Job Avoidance

28. Fordyce Percent Happy Item, soR

29. Satisfaction With Life Scale, SOR

31. Affects Balance Scale, SOR

$\overline{03}--$

$-05-02--$

$\begin{array}{lll}-09 & -00 & -13\end{array}$

$\begin{array}{llll}03 & 31 & 03 & 15\end{array}$

$\begin{array}{lllll}-17 & 09 & -03 & 16 & 26\end{array}$

$\begin{array}{llllll}04 & -14 & 20 & -05 & 11 & -16\end{array}$

$\begin{array}{lllllll}-06 & -01 & 08 & 08 & 31 & 16 & 24\end{array}$

$\begin{array}{llllllllll}07 & 28 & 02 & -02 & 16 & 13 & -01 & 03\end{array}$

$\begin{array}{lllllllll}07 & 28 & -02 & -02 & 16 & 13 & -01 & 03 & -\end{array}$

$\begin{array}{lllllllll}-05 & 09 & -11 & 16 & 21 & 20 & -04 & 09 & -05\end{array}$

$\begin{array}{llllllllll}07 & -26 & 02 & -13 & -22 & -27 & 09 & -07 & -11 & -10\end{array}$

$\begin{array}{llllllllllll}17 & -26 & 03 & -20 & -21 & -13 & 16 & -09 & -04 & -22 & 07 & --\end{array}$

$\begin{array}{rllllllllllll}-03 & 01 & -03 & 18 & 08 & 06 & -03 & -01 & -09 & 11 & -08 & -29 & - \\ -08 & 01 & -04 & 17 & 11 & 12 & -04 & 02 & -05 & 13 & -12 & -19 & 50\end{array}$

$\begin{array}{llllllllllllll}-08 & 01 & -04 & 17 & 11 & 12 & -04 & 02 & -05 & 13 & -12 & -19 & 50 & - \\ -07 & -06 & -05 & 14 & 04 & 02 & -02 & 03 & -12 & 05 & -05 & -24 & 77 & 57\end{array}$

$\begin{array}{lllllllll}-04 & -07 & -10 & 11 & 03 & 01 & -10 & -02 & -13\end{array}$

32. Job Dysfunctional Attitudes, soR

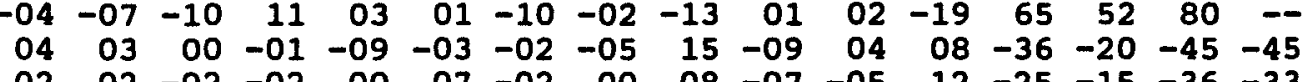

33. Dysfunctional Attitude scale, sor

$\begin{array}{lllllllllllllllllllll}02 & 02 & -02 & -02 & 00 & 07 & -02 & 00 & 08 & -07 & -05 & 12 & -25 & -15 & -36 & -33 & 51 & -\end{array}$

Note: Decimals are omitted. Correlations greater than .13 are significant at the .05 level

(two-tailed). SOR=significant Other Report. 
Table 2

Full Data Measurement Model Parameter Estimates

\begin{tabular}{lll}
\hline & & Source \\
Construct and Measure & $\begin{array}{l}\text { Factor } \\
\text { Loading }\end{array}$ & Factor \\
\hline
\end{tabular}

Dysfunctional Thought Processes

Dysfunctional Attitude scale (DAs)

$.80(.08)$

DAs, significant other Report

$.35(.07)$

$-.25(.07)$

Job Dysfunctional Thought Processes

$\begin{array}{llll}\text { Job Dysfunctional Attitude scale (JDAS) } & .75(.08) \\ \text { JDAS, Significant other Report } & .33(.07) & -.45(.07)\end{array}$

Subjective Well-being

$\begin{array}{lll}\text { Affects Balance Scale (ABS) } & .84(.06) \\ \text { Underwood and Froming Scale (UF) } & .94(.05) \\ \text { Fordyce Percent Time Happy Item (FOR) } & .89(.05) \\ \text { Satisfaction With Life Scale (SWLS) } & .68(.06) \\ \text { Positive Affectivity Scale } & .60(.06) \\ \text { Negative Affectivity Scale } & -.74(.06) & \\ \text { ABS, Significant Other Report } & .51(.06) & .67(.05) \\ \text { UF, Significant Other Report } & .51(.06) & .82(.05) \\ \text { FOR, Significant Other Report } & .45(.06) & .66(.06) \\ \text { SWLS, Significant Other Report } & .38(.07) & .47(.06)\end{array}$

Job satisfaction

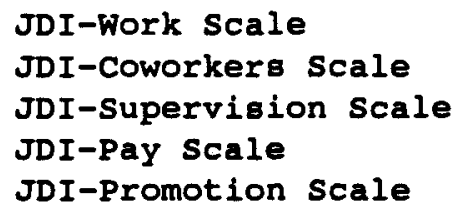

$$
\begin{array}{llll}
.84(.06) & & \\
.94(.05) & & & \\
.89(.05) & & \\
.68(.06) & & \\
.60(.06) & & \\
. .74(.06) & & \\
.51(.06) & .67(.05) \\
.51(.06) & .82(.05) \\
.45(.06) & .66(.06) \\
.38(.07) & .07(.06)
\end{array}
$$

Note: Standard errors are in parentheses.

All estimates are significant at $\mathrm{P}<.01$. 
Figure Captions

Figure 1. Hypothesized Structural Model.

Figure 2. Structural Estimates Using Self-Report Data.

Figure 3. Structural Estimates Using Self-Report and Significant Other Data. 


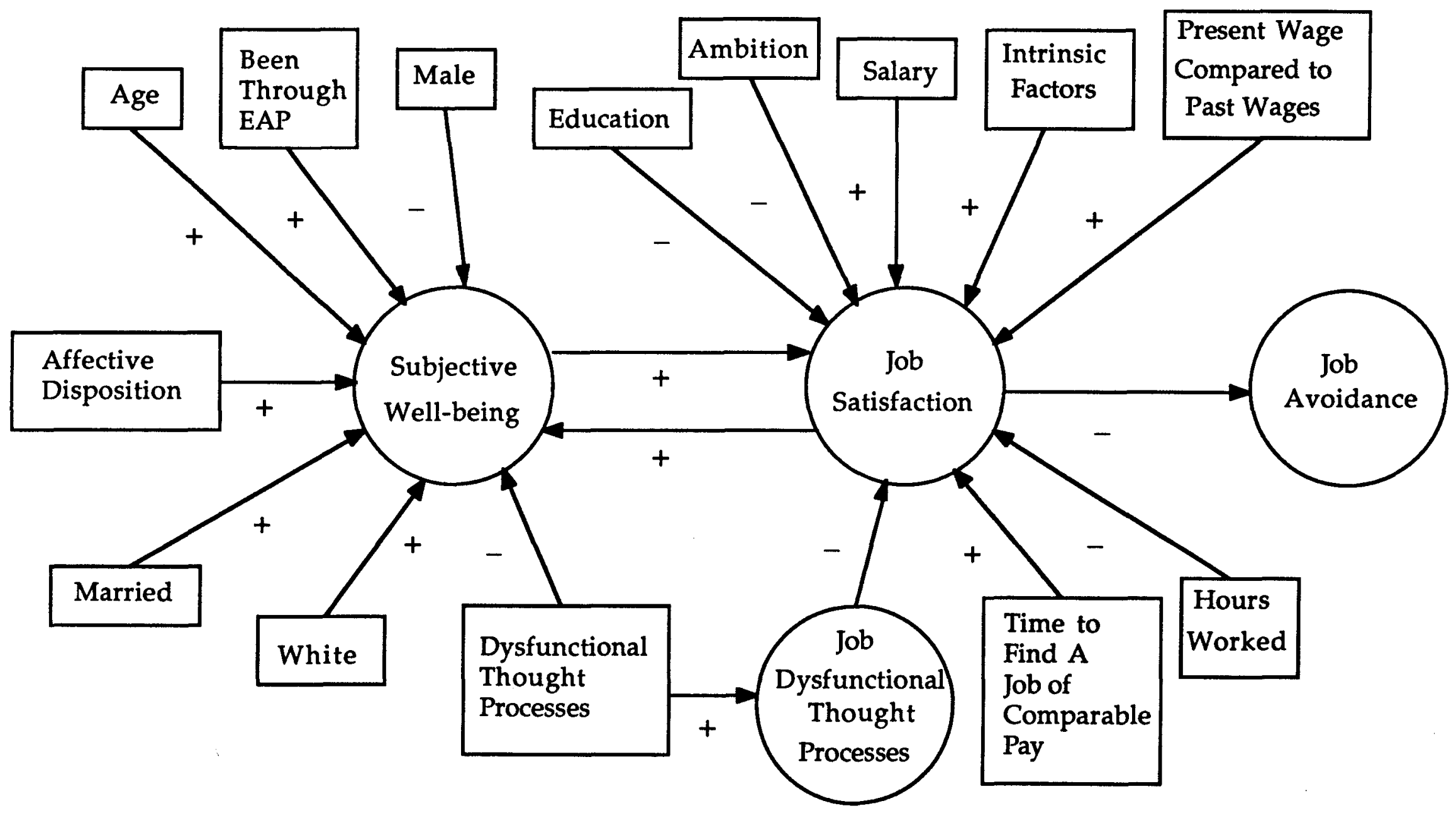




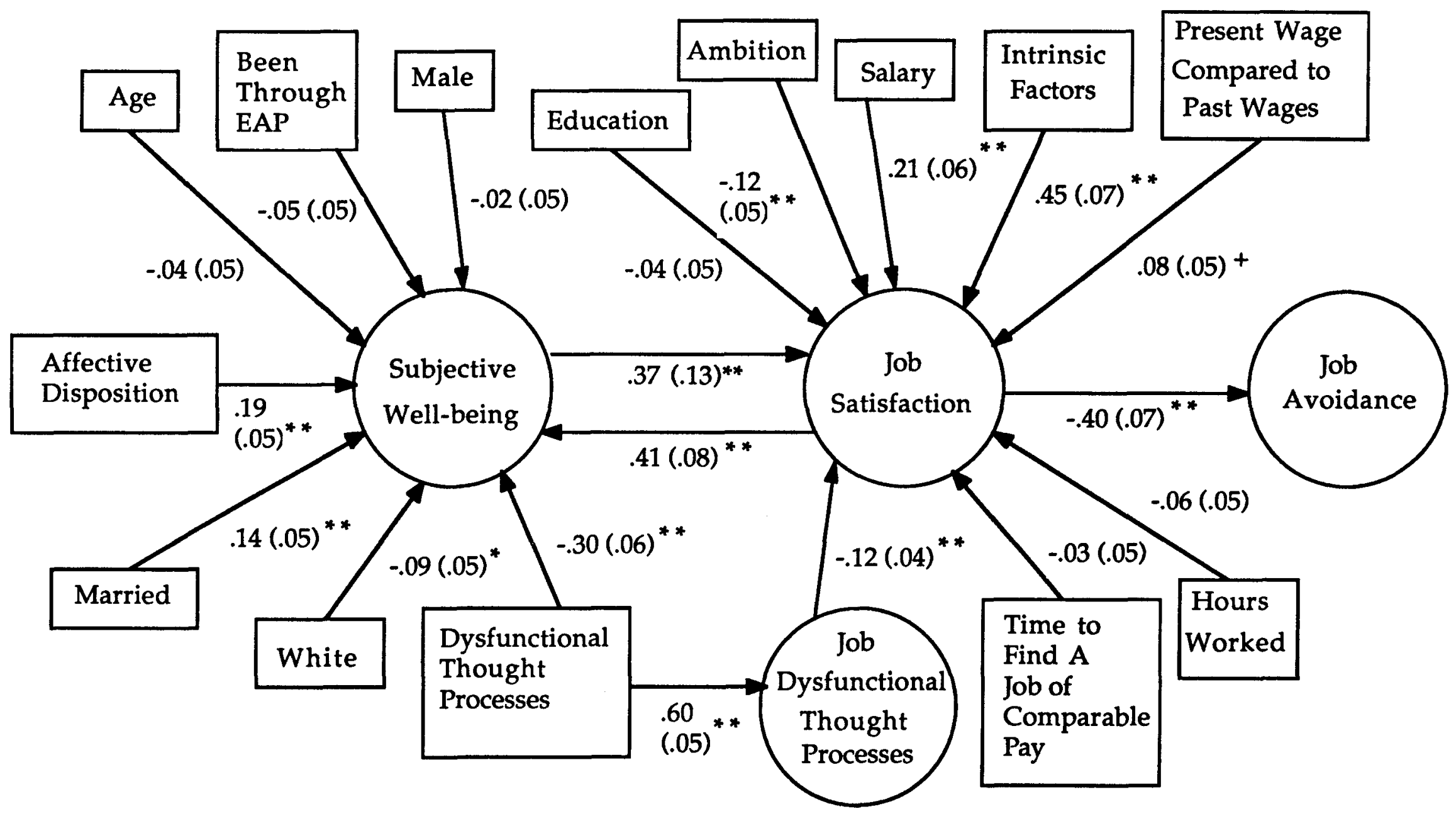

Note: ${ }^{+} \mathrm{p}<.10 ;{ }^{*} \mathrm{p}<.05 ;{ }^{* *} \mathrm{p}<.01$ (one-tailed tests)

Standard Errors are in Parentheses 


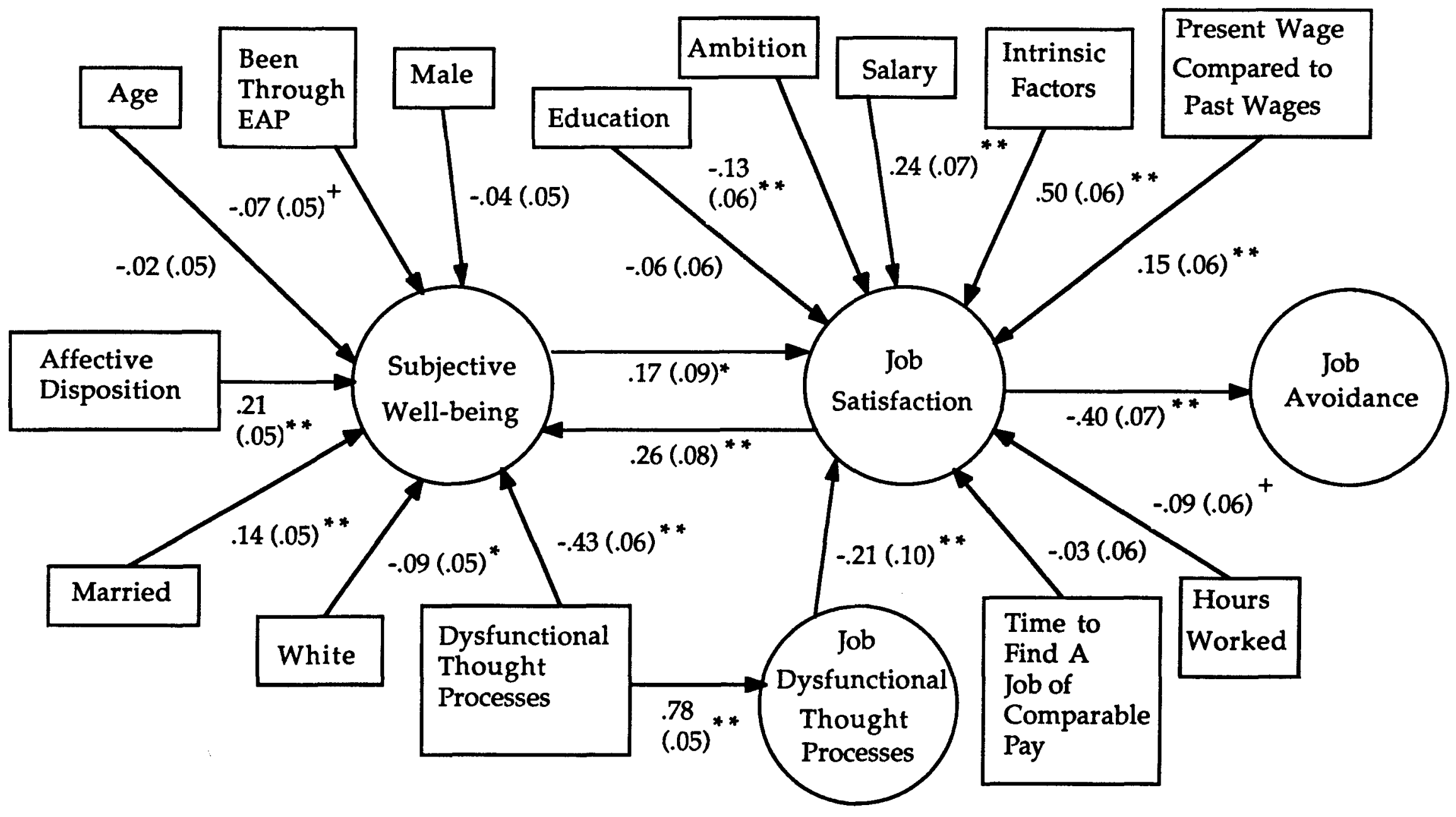

Note: ${ }^{+} \mathrm{p}<.10 ;{ }^{*} \mathrm{p}<.05 ;{ }^{* *} \mathrm{p}<.01$ (one-tailed tests)

Standard Errors are in Parentheses 